\section{A Word in Defence of Physicists.}

Two passages in NATURE of April i4th show that the supposed opposition between geologists and physicists is not forgotten. This feud can only inpede the advancement of truth.

Prof. Duncan, in his irstructive paper on Dr. Carpenter's Report, writes thus :- "Physicists have propounded theories which have been accepted by some geologists, but they are looked upon as doubtful hypotheses by others. Palæontologists and such theories have been constantly at issue. The theories involving pressure, and the lrardness of deep-sea deposits, will suffer from the researches; but many difficulties in the way of palæontologists will be removed."

I cannot think that either of the "theories," to which allusion appears to be madle, can ever have been accepted by any one who understood the nature of fluid pressure. The tissues of a living being inhabiting the depths must necessarily be permeated by liquids at the same pressure as that of the water withont. Hence no crushing effect can be produced. So, too, the particles of mull or sand at the bottom of the ocean are buoyed up by water at the same pressure as that by which they are forced down, and they sink only by the difference of weight between themselves and the dense water; so that the ooze at a profound depth ought actually to lie lighter than beneath shallower water. These considerations have always occurred to me when reading about the misconceptions to which Prof. Duncan alludes. But what I wish to point out is, that it is not the deductions of physicists which are overthrown, but the fancies of those who are not physicists, which were always opposed to physical principles.

Mr. Wilson's letter about "geological time" may possibly elicit a reply from Professor Pritchard. But why is Sir W. Thomson's name introduced into the heading? And does $\mathrm{Mr}$. Wilson intend to tell us that $\mathrm{Mr}$. Darwin considers natural selection incompetent to produce the human eye? For unless $\mathrm{Mr}$. Darwin admits direct desicn in the arrangement of the human eye, it does not appear how Mr. Pritchard's lapsus in seeming to include man among the Articulatc, can vitiate his argument as against Darwin.

O. FISHER

\section{Heat Units}

IN No. 24 of NATURE (April I4) Mr. Thomas Muir calls atention to the inconvenience arising from the want of some uniform and generally recognised mode of expressing qualities of heat. As there can be no question that the inconvenience is a real one, I venture to suggest as one remedy for it, the employment of the following terms, namely-

$$
\text { grain-degree, }
$$$$
\text { pound-degree, }
$$

gramme-degree

kilogramme-degree,

to denote respectively the quantities of heat required to raise the temperature of one grain, pound, gramme, or kilogramme of water from $0^{\circ}$ to $I^{\circ}$ Centigrade. These expressions are used in the article HEAT, in Watts's "Dictionary of Chemistry"; and having been for several years in the habit of using them in my lectures, I am able to say from experience that the employment of them greatly facilitates statements relating to quantities of heat.

It appears to me to be in favour of these terms, as compared with Mr. Muir's "therm," "kilotherm," \&c., that they enable us to do without the formation of any new word, that they are self-interpreting, and that by means of them quantities of hea can be expressed with reference to the British or to the metrical standards of mass, with equal facility.

University College, London, ApriI 25. G. C. FOSTER

\section{The Sun's Chromosphere}

Is there any way, by means of an ordinary telescope with coloured glasses, of seeing the red prominences on the sun's edge - that is, without a spectroscope? If so, what coloured glasses ouglit to be used? In one of the former numbers of NATURE, an observer saw, with only a telescope, what he believed to be these prominences; the sun was near the horizon, a series of rose-coloured undulations became visible, unconnected, as supposed, with atmospheric disturbance, and which it was suggested might be due to the red flames of the chromosphere.

A.

\section{Lefthandedness}

IN a letter on this subject by J. S., in this week's number of NATURE, the hypothesis is mentioned that left-handed persons may owe their peculiarity to a transposition of the viscera, or at least of the great arteries of the ipper limbs. This supposition, which has been more than once advanced, is certainly not true. Several cases of transposition of viscera are on record in which the persons affected were right-handed. One was recorded by M. Géry (quoted in Cruveillier's Anatomie, tome I, p. 65, note), another by M. Gachet (Gazette des Hopitaux, Aug. 3I, 186I), and a third in the Pathological Transactions, vol. xix., p. 447 .

Your correspondent's opinion seems probable that righthandedness is the result partly of hereditary, partly of individual education, and is intimately associated with the more complex functions of the hand.

April 18,1870

P. S.

\section{THE ABRADING AND TRANSPORTING POWER OF WATER}

\section{II.-FRICTION OF WATER}

O $N$ a former occasion the abrading and transporting power of water (which is supposed to increase as the velocity increases, but to decrease as the depth increases) was considered from a mechanical point if view, and arguments were brought forward to show that water rolls rather than slides. The question then arises-

III. How does flowing water obtain this rolling motion? The reply to this is, By friction.

Take, for example, the rifling of a gun; we all know that it is owing to the spiral grooves or prominences in the chamber that the shot gets its spinning motion; but supposing the shot be a sphere, and fired from a smooth bore, it has not this rotatory motion at right angles to the line of flight, and no great dependence can be placed on its accuracy, but it may rise or fall, pass to the right or left, all depending on which side of the gun's mouth the shot touched when passing out, for so will it revolve. Should it ricochet, it will, when nearly spent, be observed to roll over the ground, and this is all caused by the friction offered by the resistance of the ground with which it came in contact. And what reason can there be assigned against water adopting this most simple of all laws for bodies in motion; and is it not owing to this that water in a cistern takes a circular motion when escaping through an orifice in its bottom, or presents a cork-screw appearance when poured out of a small vessel? Again, on the large scale, with rapid currents such as in the Pentland Frith, what but this circular motion of the stream can cause that boiling apappearance given to the water, which everyone must have observed who has navigated waters where there is a strong tideway? And cannot this explain why there should be an enormous breaking sea at the point where the heavy swell of the Atlantic meets the ebb tide; and does not this rolling motion given to the tide, acting in an opposite direction, check the oscillations of the Atlantic swell, causing those huge breakers so well known to the Orcadian boatmen?

Supposing every particle of water to be a sphere in itself that can roll independently, and that a number of them being collected together form a larger sphere, which also rolls, and so on, then the diameter of the spheres increases with the depth, be it ever so great. Consequently, the facility for rolling will also increase, so that the deeper and broader a stream is--that is, the farther the deeper and broader a stream the retarding medium (the bed and banks of a river) - the less is this rotatory motion obstructed; and does not this explain how the velocity increases with the hydraulic mean depth? The air also has a retarding effect even in a perfect calm; for where the Mississippi was very deep, it has been observed that 